\title{
Pragmatismo e senso comum
}

\section{Nelson Goldenstein}

Não há como discutir o sentido das atuais práticas de reabilitação psicossocial, sem incluir, previamente, algumas considerações psicopatológicas a propósito da perda do pragmatismo, e da deterioração da personalidade, encontradas entre certos pacientes esquizofrênicos graves.

Se, anteriormente, a psiquiatria voltava seus esforços apenas para os delírios e alucinações, hoje reconhece que muitos dos que alcançam razoável alívio sintomático acabam permanecendo socialmente isolados, desempregados, ou incapazes de retornar às suas atividades habituais, quando não se tornam incapazes até de cuidar de si mesmos. A literatura especializada não fornece explicações satisfatórias para esses problemas, sobretudo quando as principais manifestações psicóticas já foram minoradas.

Sem a ingenuidade dos anos 1960/1970, que atribuía a evolução desfavorável apenas às instituições asilares, essas questões compõem temas extremamente complexos, que envolvem diferentes paradigmas não excludentes. Trata-se de uma área que pode ser estudada desde certos referenciais filosóficos, antropológicos, psicanalíticos, neuropsicológicos e lingüísticos, até os modernos estudos neocognitivistas, que permitem incluir também uma releitura da antiga psicopatologia fenomenológica.

Tradicionalmente, a concepção de transtornos esquizofrênicos ainda envolve o velho naturalismo metafísico, que opõe natureza versus cultura, como se ambas fossem dimensões abstratas, essencialmente independentes. A utilidade desse tipo de naturalismo cai por terra quando verificamos, por exemplo, que a dete- 
rioração da personalidade é, hoje, uma condição mais rara do que no início do século XX. A mudança estatística no perfil evolutivo dos quadros esquizofrênicos parece expressar, ao menos parcialmente, o resultado da mudança de mentalidade sobre as diversas formas de exclusão social e, portanto, permite supor a existência de padrões psicopatológicos intrinsecamente culturais. ${ }^{1}$

Desde quando o conceito de Dementia praecox foi criado, estas questões envolvem diretamente o diagnóstico de esquizofrenia (Kraepelin, 1907). Ao longo de décadas, a perda do pragmatismo, e a deterioração da personalidade, têm sido os principais temas da maioria das polêmicas, tanto sobre classificação, como sobre seus supostos agentes causais.

Durante anos, acreditou-se que os transtornos esquizofrênicos seriam entidades naturais ${ }^{2}$ progressivas, e que a deterioração do afeto e vontade - suas principais marcas sintomáticas - seriam as expressões mais contundentes de um hipotético processo degenerativo, de caráter evolutivo. Na realidade, em sua origem, a Dementia praecox foi concebida como um transtorno progressivo, intrinsecamente deteriorante, e não influenciável pelas circunstâncias ambientais. Hoje, estudos de follow-up prospectivos modernos já demonstraram que não há qualquer marcha verdadeiramente progressiva nestas condições (Angst, 1988). Entre aqueles que não conseguem encontrar uma completa recuperação ao longo dos primeiros episódios psicóticos, sabe-se que após períodos individualmente variáveis, não há mais qualquer mudança progressiva na psicopatologia esquizofrênica, exceto eventuais exacerbações e/ou remissões de sintomatologia produtiva (Häfner, 1999; Hüber, 1998). Apesar destas evidências, o ponto de vista que pressupõe uma evolução progressivamente deteriorante ainda encontra certa aceitação na comunidade psiquiátrica.

Alguns fatores parecem ter determinado a consistência desta concepção, hoje incompatível com os dados empíricos mais recentes. É possível que curso e evolução fossem mais graves no início do século XX, quando a maneira de tratar os doentes esquizofrênicos era bastante diferente (Ciompi, 1984; Wing, 1987). Supõe-se também que as amostras das primeiras pesquisas realizadas eram

1. Estudos de follow-up realizados a partir dos anos 1940 demonstram mudanças estatísticas significativas no perfil clínico dos casos graves, portanto, antes do início da chamada era dos neurolépticos (Bleuler, 1980).

2. O conceito kraepeliniano de entidade natural apóia-se no modelo médico de doença: a) Manifestações clínicas; b) Substrato anatomo-patológico; c) Agente etiológico (Kraepelin, 1920). 
influenciadas por fatores externos à problemática clínica. E, finalmente, que a teoria da degeneração, na época prevalente, tenha determinado essencialmente a visão desse transtorno (Zubin, 1985). Kraepelin, por exemplo, parece haver trabalhado preferencialmente com os casos mais severos de seu tempo, particularmente com aqueles de longa permanência institucional, já em evolução cronicamente deteriorante. Sabe-se que foi a partir dos pacientes selecionados na clínica de Heidelberg que esse autor realizou seu estudo evolutivo sistemático, permitindo a classificação definitiva da Dementia praecox (Kraepelin, 1987). Aparentemente, sua amostra de pacientes foi particularmente influenciada pela severidade e cronicidade. A política de distribuição e internação dos pacientes alemães daquela época fazia com que os casos de maior gravidade fossem desviados para aquela clínica universitária, que em seguida os encaminhava para os asilos públicos (Berrios et col., 1988). Há autores que apontam para esse fato como uma das principais razões para os baixíssimos índices de recuperação encontrados entre os pacientes estudados por Kraepelin (Harding et col., 1992). Não é difícil imaginar as conseqüências práticas desse ponto de vista.

A maneira como abordamos um determinado fenômeno determina o nosso olhar (Merleau-Ponty, 2000). Na abordagem do comportamento humano, a complexidade é maior, pois aqui sujeito e objeto são demasiadamente próximos para permitir uma investigação absolutamente distante e independente. Nossa simples aproximação modifica o objeto investigado. A questão torna-se mais problemática ainda quando se considera a particular caleidoscopia da psicopatologia esquizofrênica. Além de ser uma condição de natureza obscura, ao menos parte de sua variabilidade parece ser o resultado da qualidade de nossa interação com o objeto, em diferentes momentos de seu processo de adoecimento. Assim, não é possível deixar de considerar também suas reações às nossas atitudes frente a eles.

Em parte, o movimento neokraepeliniano que vimos ressurgir mais recentemente, no início dos anos 1980, foi uma expressão desta visão, certamente pouco condizente com o resultado de pesquisas posteriores, que demonstraram possibilidades evolutivas estatisticamente mais promissoras do que as habitualmente esperadas. Na realidade, no final dos anos 1970, e início da década de 1980, acreditou-se especialmente útil considerar esquizofrênicos apenas os casos mais graves, e alguns instrumentos diagnósticos foram construídos exclusivamente com esse intuito, embora esse objetivo tenha sido relativamente pouco explicitado. O esforço em aumentar os índices de confiabilidade diagnóstica parece ter sido um dos fatores determinantes para a adoção desta estratégia, melhor divulgada a partir da terceira edição do Manual Diagnóstico da Associação 
Psiquiátrica Americana, o DSM-III. ${ }^{3}$ Naquela versão diagnóstica, definia-se o transtorno como doença crônica, invariavelmente evolutiva para estados residuais irreversivelmente deteriorados. ${ }^{4}$ Ainda que para alguns autores a utilidade desse critério tenha sido restrita apenas à elaboração de uma estratégia de pesquisa preocupada em selecionar grupos de investigação mais homogêneos, e independente de teorias a priori (Buchanan \& Carpenter, 1994), a ampla utilização daquele manual reforçou, mais uma vez, a noção dos transtornos esquizofrênicos como entidades mórbidas implicitamente progressivas e deteriorantes.

Mas se o suposto caráter progressivo dos transtornos esquizofrênicos já foi empiricamente invalidado, a deterioração da personalidade, e os vários graus de comprometimento do pragmatismo são fatos clínicos inquestionáveis. Ainda que menos freqüente nos dias de hoje, não raro encontramos pacientes trancados e isolados em suas próprias casas, incapazes até de sair à rua. Como explicar esta aparente contradição?

Desde os autores franceses do século XIX há, na clínica psiquiátrica, uma insistência em diferenciar aquelas psicoses que cursam com evolução deteriorante, das que não evoluem desta forma. Este foi o paradigma teórico dos delírios crônicos sistematizados (Berrios \& Fuentenebro, 1998). O próprio Kraepelin reconheceu essa diferenciação básica na oitava edição de seu tratado, quando definiu a paranóia como entidade clínica essencialmente caracterizada por um "sistema delirante duradouro e imutável, resultante de causas internas, o qual se acompanha de completa conservação de clareza e ordem no pensamento, vontade, e ações (Kraepelin apud Bercherie, 1989; grifos nossos). Enquanto o sistema delirante da paranóia se acompanha de uma adequada organização no pensamento, na esquizofrenia o pensamento se mostra fragmentado, de maneira geral sem clareza e ordem, acompanhado de variados graus de concomitante comprometimento do pragmatismo e vontade. Independente de querelas etiopatogênicas, a separação entre ambas categorias sempre obedeceu esta orientação psicopatológica e evolutiva. Os atuais manuais diagnósticos ainda mantêm esse mesmo critério, justificado principalmente pelas diferenças finais. Psicopatologistas desde Pinel, os psiquiatras franceses foram os primeiros a apontar para essa diferença básica (Bleuler, 1926).

3. Melhor divulgada porque o DSM-III aproveitou amplamente os critérios desenvolvidos pela Escola de St. Louis, que há anos preconizava a exigência de sintomas esquizofrênicos durante pelo menos seis meses, para poder estabelecer o diagnóstico definitivo (Berner et col., 1992).

4. O DSM-III preconizava que se questionasse o diagnóstico de esquizofrenia caso não fossem encontrados sinais de deterioração da personalidade (ibid.). 
$\begin{array}{lllllll}R & E & V & I & S & T & A\end{array}$

É possível que alguns transtornos específicos do pensamento estejam na base desse complexo deteriorante, e que o comportamento tipicamente apatoabúlico seja apenas uma de suas conseqüências possíveis. De certa forma, este foi um dos fundamentos teóricos de Bleuler, que Kraepelin finalmente aceitou a partir de 1913 (Kraepelin, 1920). A expressão mais evidente desse transtorno encontra-se na transformação da fala e do comportamento esquizofrênico, tantas vezes incompreensível. Há anos o papel dos transtornos do pensamento, e sua relação com a fala, tem sido investigado. Diversos autores vêm procurando demonstrar, de diferentes maneiras, que ambos representam comprometimentos de estruturas de pensamento e linguagem, baseados nas primeiras observações psicopatológicas de Freud (1911; 1914; 1915) e Bleuler (1911). Na prática, encontramos um comprometimento bastante específico, em que as pautas de composição do pensamento e da linguagem estão profundamente alteradas.

Há dois aspectos eminentemente humanos que permitem a articulação entre certas considerações objetivas da psicopatologia cotidiana, e alguns fenômenos de ordem subjetiva na experiência de enlouquecimento. O primeiro, refere-se ao conceito evolucionário de linguagem, função própria do aparelho psíquico e, em última instância, expressão pragmática da evolução biológica do sistema nervoso central. Trata-se de um conceito teórico fundamentalmente objetivo, relacionado com a evolução da espécie humana, que em algum dia mítico deu origem à posterior subjetividade cultural de toda a humanidade. O segundo, em contraponto, refere-se ao papel do meio ambiente e da cultura na organização do sujeito e, portanto, elementos essencialmente subjetivos na significação de mundo.

Tanto através da psicanálise, como da neuropsicologia, sugere-se que a estrutura do pensamento obedece a diferentes formas de composição, de acordo com os vários tipos de funcionamento mental. Um dos exemplos mais evidentes sobre esta diferenciação, encontra-se entre os estudos sobre a estrutura do pensamento onírico, essencialmente diferente do pensamento consciente (Freud, 1900; Luria, 1987).

Do ponto de vista fenomenológico, independente de suas diferenças formais, o atributo geral da consciência é sua intencionalidade. Por definição, toda consciência é sempre consciência de alguma coisa (Jaspers, 1913). Aparentemente, a consciência não se constitui de maneira aleatória. Em condições normais, organiza-se através de pautas de composição, supostamente determinadas pela necessidade de conjugar pressões de ordem biológica e ambiental. Sem afirmar que a consciência se reduz ao pensamento, considera-se que diferenças em sua estrutura lingüística correspondem, de uma forma ou de outra, os diferentes estados de consciência de si próprio ou do outro. Parece plausível considerar que 
esta capacidade lingüística, universal em todos os seres humanos, está para o aparelho mental como a insulina está para o pâncreas, ou as enzimas hepáticas para o fígado. ${ }^{5}$ Como capacidade universal humana, trata-se de um fenômeno semelhante ao crescimento biológico (Hauser, Chomsky e Fitch, 2002), e que obedece a leis essencialmente adaptativas. Não se pode negar que esta possibilidade se realiza através da combinação entre os recursos inatos, e as condições ambientais. Um faz parte do outro.

Como expressão pragmática do aparelho psíquico, postula-se que esta capacidade lingüística determina a forma como se compõe o pensamento, cujo objetivo final será torná-lo socialmente operativo para a mente. De acordo como se organiza, permite a elaboração de diferentes formas de consciência de significação, capazes ou não de responder "fisio-antropologicamente" pela interação do homem em seu contexto. ${ }^{6}$ Vários fatores parecem possíveis de influenciar este processo, mas o resultado final é que, em condições normais, sua estrutura mental deve compartilhar regras formais coletivas, capacitando a vida de relações.

Como função universal, a capacidade lingüística do pensamento configura a estrutura coletiva, e conjuga a intencionalidade da consciência individual como corpo social. Enquanto coletivamente compartilhada, a consciência de significações se traduz pela vivência familiar e subjetiva de senso comum, universalmente experimentada no dia-a-dia das relações individuais.

Do ponto de vista filogenético, desde suas origens o sistema nervoso exerce a função adaptativa dos seres vivos com o meio ambiente. Se, como órgão de contato revela a mesma origem embrionária que a pele, é na articulação das dimensões biológica e ambiental, sob a forma de inserção sociocultural, que se constitui como aparelho psíquico. Como padrão universal, articula-se em uma trama de significações culturalmente pré-formadas. O aparelho psíquico se organiza como rede de relações e, conseqüentemente, como linguagem mediadora dos diferentes sinais sociais de comportamento adaptativo. Este é o sentido formal da linguagem e do pensamento consciente.

5. O estudo do pensamento lingüístico, como função pragmática do aparelho psíquico, não anula a subjetividade do comportamento humano. Sob a forma de linguagem, o pensamento constituiu a cultura. Mas é em sua universalidade objetiva que encontramos as bases do aparelho mental.

6. Segundo a biografia de John Nash, Nobel de economia de 1994, esse matemático desenvolveu sua famosa teoria sobre jogos sociais quando começou seu processo de desconstrução das formas compartilhadas de significação sobre o comportamento social, e recompôs uma nova consciência de significações. Para tanto, vale a interessante leitura de seu discurso para a cerimônia do prêmio Nobel (Nash, 1994). 


\begin{tabular}{llllll|l}
$R \quad E$ & $V$ & I & T & A & \\
LATINOA M ERICANA & \\
DE PSICO PATO LOGIA & \\
F U N D A M E N T A L & \\
ano IX, & n. 4, dez/2006 & \\
\hline
\end{tabular}

Nos primórdios da vida, esta organização compartilhada se constitui a partir do outro. Equipado com uma mente dotada de um “instinto lingüístico” (Pinker, 2002), o ser humano desenvolve sua estrutura inata através do meio em que vive. Seja como gramática (Hauser, Chomsky e Fitch, 2002), ou como estrutura universal de pensamento (Lévy-Strauss, 1975), o ser humano carrega as bases do que vem a se desenvolver no seio da consciência de significação coletiva. É apenas através desse processo compartilhado que se viabiliza a capacidade de comunicação e uma determinada forma de pensamento consciente. ${ }^{7} \mathrm{~A}$ forma como isto ocorre obedece às características culturais locais, mas é sua estrutura universalmente inata que viabiliza a trama coletiva do comportamento humano. A capacidade de articulação social do pensamento se define através da assimilação e organização de regras formais compartilhadas. Este é o trabalho da cultura.

No mundo de relações, várias condições parecem abalar essa organização mental coletiva. Em recente pesquisa utilizando dados epidemiológicos do "Estudo sobre as Determinantes da Evolução dos Transtornos Mentais Severos”, a OMS revelou que a incidência de psicose aguda breve é dez vezes mais alta nos países em desenvolvimento do que nos países já industrializados (Susser \& Mojtabai, 1999), sugerindo o papel da instabilidade social como elemento desorganizador. A constatação da variação da incidência de transtornos esquizofrênicos, maior entre minorias, como caribenhos e africanos moradores no Reino Unido, e menor em suas respectivas terras natais (Eaton, 1999) é, acima de tudo, outra evidência sobre a importância que o meio ambiente parece exercer nos processos mentais, patológicos ou não. Neste sentido, inúmeros trabalhos antropológicos e etnopsiquiátricos apontam para a associação entre rápidas transformações sociais, e aparecimento de quadros psicóticos agudos (Devereux, 1973; Murphy, 1976). Durante os anos 1970 e 1980, no auge da grande leva migratória de nordestinos para o Rio de Janeiro, o IPUB atendia com relativa freqüência casos de psicoses delirantes agudas e transitórias, com remissão sintomática total em poucas semanas.

De uma maneira geral, as pesquisas sugerem o importante papel das estruturas sociais na organização e desorganização do pensamento compartilhado, independente de categorias diagnósticas. Doentes ou não, somos no mundo, e a psiquiatria levou muitas décadas para reconhecer isto.

7. Estudos com surdo-mudos congênitos, bem como com crianças que passaram a vida privada de contato social, revelam a importância da interação social na organização do pensamento (Pinker, 2002). 
Ao longo do século passado, diversas escolas teóricas puderam indicar como certas vivências primárias de satisfação se associam e constituem o processo de aprendizagem pelo outro, definindo as formas essenciais de interação social na estruturação do sujeito. ${ }^{8}$ É esta alteridade básica que caracteriza o pensamento como estrutura articulável e, portanto, permeável às diferentes formas de intervenção social.

Por outro lado, quando, por qualquer motivo, há desorganização da consciência, verifica-se a concomitante perda de sua intencionalidade, revelada pelo comprometimento do pragmatismo, ou, melhor, de sua função operante. Evidentemente, uma nova reorganização permite a recuperação de seu papel intencional. Mas quando examinada pelo ângulo de sua inserção social, e não apenas de sua intencionalidade, essa reorganização só é socialmente articulável se obedecer, minimamente, às mesmas regras formais coletivas. Em outras palavras, se recompuser a mesma organização compartilhada anterior. Caso contrário, ainda que formalmente organizada, sem o sistema conceitual compartilhado, a consciência de significações será sempre idiossincrásica, e o pensamento não será socialmente articulável, apesar de recuperar sua tarefa pragmática e intencional. Assim, do ponto de vista clínico, é essencial reconhecer e diferenciar o pensamento desorganizado daquele não compartilhado socialmente, como o pensamento de certos delirantes, pleno de neologismos, idiossincrásicos, e quase incompreensíveis.

Não há condição mais grave para compreender a importância da linguagem na capacidade em lidar com o mundo, do que nos transtornos esquizofrênicos. Como em um vôo às cegas, os pacientes mais graves se sentem perdendo uma subjetiva capacidade para compreender os códigos de significação da realidade que os rodeia. Quem quer que escute as queixas dos pacientes esquizofrênicos, poderá confirmar, empaticamente, o mal-estar subjetivo relacionado ao sentimento de estranheza e distanciamento em relação ao mundo compartilhado.

É através de um processo de linguagem específico, ou melhor, de um intrincado processo de significação, que duplicamos o mundo. Representamos a realidade para planejar psiquicamente nossos atos. É assim que exercemos nossa ação voluntária sobre ele, e é justamente essa habilidade que nos diferencia dos outros animais (Luria, 1987). Os mais arcaicos códigos de comportamento humano, como os ritos e tabus, surgiram justamente como resultado da

8. Como, por exemplo, as primeiras experiências de satisfação e frustração do bebê, durante a fase de aleitamento materno (Stern, 1992). 
relações sociais, promove uma profunda transformação, junto com os tratores que demolem a pequena rede das velhas construções interligadas. Evidentemente, os mais frágeis não acompanham tão facilmente essas rápidas e inevitáveis transformações. O velho dono de uma tradicional casa de banhos e massagens representa a tradição, e é o primeiro a sucumbir. Nesse contexto, seu filho, nitidamente anormal, perde seu espaço social, e entra em uma crise de agitação psicomotora. A antiga comunidade, que tradicionalmente usava seus próprios recursos para lidar com os casos de adoecimento, não tem mais outras formas de intervenção, exceto chamar a ambulância com os enfermeiros psiquiátricos, que chegam para conter e internar o ensandecido rapaz, ${ }^{12}$ até então perfeitamente inserido na coletividade local. O rapaz entrou em crise quando se desfez a rede de suporte que amarrava as diferenças. Seu espaço social desapareceu de um dia para o outro. De forma empática, é possível vivenciar o sentimento de desamparo naqueles momentos que antecedem a demolição. Sem seus referenciais, o rapaz se desespera.

Mal comparando com outras formas de códigos mediadores de comportamento social, até mesmo as formigas podem se tornar temporariamente atônitas, e apresentar momentânea "agitação psicomotora", se alguém arrastar o dedo e apagar o rastro químico que determina a trilha coletiva, espécie de código norteador que cada uma deixa marcado pelo chão. ${ }^{13}$ Hábitos, costumes e valores não são códigos de significação e direção das relações sociais? É a instauração de determinadas regras compartilhadas que organiza a humanidade e, simultaneamente, define a estrutura da consciência universal. Fenomenologicamente, a forma da consciência é determinada pelas regras de organização lingüística universais ao ser humano, e a trama cultural é a melhor expressão dessa estrutura coletiva.

Espécie de padrão de resposta preferencial, ${ }^{14}$ a produção psicótica parece surgir sob a ação de temores básicos, aparentemente remediando rupturas, e comprometimentos subjacentes. Seu papel absolutamente secundário é confirmado quando se reconhece que as manifestações psicóticas são os elementos mais ins-

12. Apesar de ainda conhecermos pouco sobre o sistema psiquiátrico chinês, sabe-se que os cuidados ainda são eminentemente comunitários, exceto nas grandes metrópoles, como Xangai e Beijing, onde o número de leitos hospitalares psiquiátricos é relativamente maior (Parry-Jones, 1986).

13. Do ponto de vista etimológico, delirar significa sair da trilha (Houaiss, 2001).

14. Ao estilo do padrão biológico de resposta preferencial, de Bonhöffer (Hoch, 1912). 
táveis e episódicos do adoecimento geral (Andreasen, 1997). Mas é a dissolução de uma ordem específica de significações que permite abordar uma das questões psicopatológicas fundamentais dos transtornos esquizofrênicos. É para esta perda, ou ausência de significação, com subseqüente modificação estrutural do pensamento e da fala que dirigimos nossas preocupações terapêuticas. Nestas ocasiões, em geral, encontramos pacientes confusos e atormentados com um mundo que não estão conseguindo compreender, operar, nem compartilhar.

A prática clínica revela uma particular e dolorosa perda da vivência subjetiva de senso comum, conforme se agravam os fenômenos esquizofrênicos. A simples ajuda no acompanhamento solidário, no cumprimento de suas tarefas cotidianas, ou no alívio e diminuição do estresse provocado pelo sentimento de estranheza, solidão e desamparo, parecem diminuir a intensidade da fenomenologia psicótica, bem como da desorganização do pensamento, às vezes até mesmo sem intervenção medicamentosa. Não se trata de afirmar, ingenuamente, que nossos esforços devem se voltar apenas para a tranqüilização emocional, mas de reconhecer que a eclosão da fenomenologia produtiva pode ser o resultado final de situaçõeslimite, independente de sua natureza, possivelmente heterogênea.

As experiências pioneiras de Mosher, realizadas na Califórnia durante os anos 1970, através da conhecida Casa de Soteria, e replicadas nos anos 1980 na Casa de Soteria Berner, por Ciompi et col. (1992), ${ }^{15}$ permitem reconhecer o papel primordialmente desestruturante do estresse, e a eclosão de sintomatologia psicótica. Se quisermos ser rigorosos em nossas considerações clínicas, e manter uma prática baseada em evidências empíricas, é preciso admitir que a única certeza, ao menos em relação às medicações de ação antipsicóticas, é que elas funcionam dentro da velha tríade descrita por Delay \& Deniker (1961): a) produzindo um certo tipo específico de tranqüilidade e/ou indiferença emocional, b) diminuição dos impulsos instintivos, e c) sedação. Se esta tranqüilização ocorre por intervenção específica em vias dopaminérgicas, ou em algum outro modelo de supostas vias neuroquímicas, trata-se de uma questão semântica, ou melhor, da maneira como formulamos nossos modelos de significação sobre as manifestações clínicas observadas. Na realidade, a observação empírica indica que existem diversas formas eficientes de tranqüilização emocional, além da medicamentosa. Elementos subjetivos e intersubjetivos, presentes nas relações

15. Em ambas experiências, organizou-se ambientes artificialmente dotados de condições onde pudessem minimizar-se qualquer stress possível, como forma de observar o "comportamento" da desorganização e sintomatologia psicótica. O resultado final foi a redução das doses de medicação neuroléptica. Os casos de remissão sintomática, sem utilização de medicações, foram ocorrências estatisticamente significativas. 
afetivas, e culturalmente determinadas, podem ser uma dessas formas. Todas podem agir de forma concomitante, e mutuamente potencializadoras.

Se o processo inicial é, ou não, resultado da interação entre condições constitucionais e ambientais, ao menos a evolução deteriorante entre certos pacientes esquizofrênicos parece ser uma função eminentemente social. Além do que habitualmente se observa na prática assistencial, os estudos de seguimento transculturais da OMS também alcançaram essas mesmas conclusões, replicadas quase dez anos depois (WHO, 1979; Sartorius et col., 1986). Mesmo que os transtornos esquizofrênicos sejam universalmente identificados em todas as partes do mundo, sua evolução varia de acordo com cada cultura.

Há várias formas de compreender essa variação evolutiva encontrada nos estudos da OMS. Uma delas é a idéia de que o mundo contemporâneo exige formas de pensamento pautadas em níveis de abstração que o(s) transtorno(s) esquizofrênico(s) freqüentemente destrói. Do ponto de vista etiopatogênico, não seria sequer absurdo supor que certas pessoas não conseguem acompanhar a fluidez abstrata dos códigos de regulação das sociedades contemporâneas e, desta forma, mostram-se particularmente vulneráveis às complexas relações hierárquicas de significação, tornando-se menos capacitadas para impor sua normatividade sobre certos ambientes que os cercam.

O reconhecimento dos sintomas "S" do sistema CATEGO/PSE, ${ }^{16}$ presentes em todos os nove centros colaboradores internacionais da OMS, demonstra que a psicose esquizofrênica (aqui compreendida como fenômeno secundário) é uma possibilidade universal do ser humano. Presente nos "quatro cantos do mundo" (Sartorius, 1986), trata-se de algo como uma antropose, como quis Binswanger (1977). Em outras palavras, enlouquecer é um fenômeno humano. Mas a variação estatística no curso evolutivo, sugere algo mais: que a doença que conhecemos hoje como esquizofrenia, de curso tipicamente deteriorante, pode ser uma doença do mundo moderno. ${ }^{17}$

Ainda sabemos muito pouco sobre as causas dessa misteriosa forma de adoecer psicótico. Tampouco sobre esse suposto processo primário de comprometimento das estruturas dos códigos de linguagem. Mas a observação clínica revela que a dissolução da função adaptativa de nossas formas de

16. Estes sintomas são categorias operacionalmente padronizadas para fins comparativos. Em sua grande maioria, os sintomas $\mathrm{S}$ correspondem aos sintomas de primeira ordem para o diagnóstico de esquizofrenia de K. Schneider (Wing et col., 1975).

17. Segundo Devereux (1973), a esquizofrenia é a doença do mundo moderno, das sociedades em rápido processo de transição. 


\section{$\begin{array}{lllllll}R & E & V & I & S & T & A\end{array}$

pensamento é individualmente variável, e influenciável por diversos fatores, como os tipos de laços e articulações sociais, de reinserção social e, sobretudo, do suporte e significação cultural que o sofrimento psíquico recebe de seus pares comunitários. Enfim, de todos os elementos integradores que compõe a pessoa.

Mesmo que ocorram semelhantes formas de modificação nos padrões estruturais de pensamento, ou que estas referidas transformações possam ser verificadas em qualquer cultura, em diferentes partes do mundo, os fenômenos de desorganização e/ou de produção psicótica evoluem de maneira variável, de acordo com aspectos subjetivos relacionados a questões individuais e culturais. Aparentemente, nos países em desenvolvimento, por exemplo, as formas agudas e episódicas de adoecimento esquizofrênico são muito mais comuns do que as formas crônicas, de pior prognóstico (Jablensky, 1999). Curiosamente, as formas mais graves de esquizofrenia, classicamente conhecidas como esquizocáricas, e particularmente caracterizadas pela acentuada deterioração, quase não são mais encontradas na clínica cotidiana. Embora durante os anos 1930, 1940 e 1950 essas formas fossem os exemplos paradigmáticos do modelo degenerativo (Fish, 1957), seu atual desaparecimento reforça a observação de que a deterioração pode ser um simples artefato social.

Sem qualquer preocupação interpretativa sobre o conteúdo subjetivo dos sintomas psicóticos, indicamos onde se situa o esforço compensatório dos pacientes, assim como o núcleo do processo de deterioração da personalidade. Enfocando as estratégias de sobrevivência a partir do papel regulador da cultura, assim como pelas formas de estruturação das relações sociais, encontramos os elementos integradores entre o eu e a realidade. A vivência de senso comum, alcançada a partir dos códigos compartilhados de significação social, parece ocupar um lugar de destaque no sentimento de estruturação do eu, de tranqüilidade e razoável harmonia emocional, de realização em seu percurso existencial. É neste mesmo sentido que podemos compreender os resultados catastróficos das práticas de exclusão social, e confinamento institucional, locais onde são encontrados os maiores índices de deterioração da personalidade.

Hoje, os novos dispositivos de atenção psicossocial devem dirigir seus esforços terapêuticos para a recuperação do sentimento de senso comum, compreendido como elemento primordial para a recomposição do sentido de unidade e existência do sujeito. Qualquer programa de assistência extra-hospitalar deve ter bem clara a noção de que cada paciente sabe, melhor do que ninguém, a dimensão do esforço para manter alguma forma de controle normativo sobre seu percurso existencial. Cientes desta preocupação universal, os programas podem reconhecer que tentativas de adaptação malogradas somam-se à confusão 
e perplexidade, perpetuando o comportamento de desistência que temos denominado como "abandono de si mesmo" (Goldenstein, 2002).

A atividade clínica ensina que quando um indivíduo perde a função pragmática do pensamento (a organização formal construída pela interação com a rede social de significações) e, ao mesmo tempo, não tem rede de sustentação social, apresenta o que denominamos de deterioração dos hábitos sociais, do comportamento, e da personalidade em geral. Nestes casos, freqüentemente observamos um quadro de perplexidade e desorganização, se não provocado, ao menos ampliado pela ansiedade e desespero de desamparo. O convívio sistemático mostra que ao se desorganizar, via de regra ocorre uma reconstrução formal do pensamento, em geral de conteúdo delirante, supostamente capaz de estabelecer novos referenciais, eventualmente reconstituindo parcialmente, ou não, outra estrutura de pensamento e linguagem.

Assim como já se demonstrou, a complexidade dos padrões arcaicos de pensamento concreto entre os povos de comunidades tribais (Lévy-Strauss, 1986), as vias associativas alternativas do pensamento esquizofrênico revelam uma complexidade raramente encontrada em outras situações, embora freqüentemente inadequados para os padrões de abstração do mundo contemporâneo. Muitas vezes, estados de aparente empobrecimento do pensamento são, na realidade, resultado de grande confusão e desorientação em relação aos referenciais sociais abstratos, inalcançáveis através dessas novas pautas de significação de mundo. É notável que, com o passar do tempo, a mudança estrutural pode transformar o linguajar de tal forma que surja um dialeto variante da língua original, pleno de neologismos e frases incompreensivelmente idiossincrásicas. Embora pareça o contrário, este novo linguajar não representa uma necessária desorganização do pensamento, exceto quando não consegue cumprir sua intencionalidade. Supõe-se que uma "neo” organização semântica seja a expressão normativa do aparelho psíquico para dar conta de um processo primário de dissolução das redes de significação compartilhada. O que a psicopatologia clássica denomina de cisão secundária do pensamento parece ser, na realidade, a expressão de um novo funcionamento do pensamento consciente, supostamente regulado sob pautas semelhantes às do pensamento onírico. Não se trata de resgatar, ou negar, a antiga afirmação de que o pensamento esquizofrênico segue o processo psíquico primário, ou de que ele é a expressão de um processo frontal. O principal é reconhecer que, sob novas pautas de reorganização, o fluxo da fala entrecortada parece ser o resultado de sua inadequação funcional. A fala é uma função pragmática do pensamento socialmente compartilhado, e as regras do pensamento onírico não permitem que seu conteúdo seja traduzido adequadamente pelos recursos da fala, instrumento essencialmente social. 
Estas considerações reforçam a suposição de uma patologia com profundas repercussões em níveis comunicacionais. Se estivermos corretos, quanto mais a trama de linguagem estiver modificada, ${ }^{18}$ maiores serão as conseqüências em seu pragmatismo, e menores as chances de uma comunicação eficaz. Sem leitura de mundo, e formulando o pensamento apenas em pautas de significação primária (concreta), as associações serão apenas em nível de representação substantiva. Em um linguajar sintático, esta nova organização semântica ocorre com uma profunda mudança predicativa. Cada adjetivo do predicado, por exemplo, será sempre um neo substantivo, de forma que as características de cada substantivo serão sempre adjetivadas por um novo substantivo. Neste caso, cada objeto (ou representação primária) só pode ser representado por ele próprio, porque o sujeito não tem capacidade de incluir este objeto em uma categoria hierárquica mais abrangente do que ela mesma. Para utilizar um vocabulário neocognitivista, o sujeito torna-se incapaz de reconhecer os objetos contextualizados em uma rede hierárquica de significações (Searle, 1997). Quanto mais substantivado for o pensamento do indivíduo, mais incapaz ele se torna para ler e entender o mundo. Em seu descompasso com a ordem de significações, mistura um novo universo de significações idiossincrásicas, pautadas pela regra geral de substantivação de tudo, independente de seu nível de inteligência. A idiossincrasia do pensamento esquizofrênico se assemelha ao pensamento daqueles povos que Malinovski descrevera. Esses só podiam comunicar uma idéia quando o outro conseguia ver a referência correspondente na situação concreta natural. Nesse caso, portanto, era impossível entender de que falavam esses povos, quando não se podia ver a situação, nem os gestos, porque era somente com o conhecimento do contexto e da entonação que a palavra tomava um determinado significado (Luria, 1987).

Independente de especulações etiopatogênicas, não é impossível supor que cada doente possa encontrar um ponto de equilíbrio sustentável em diferentes estágios fenomênicos desta nova estruturação da linguagem, revelando novas formas de significação, e níveis de adaptação social possível. Aparentemente, é o que verificamos com especial freqüência em comunidades e seitas religiosas, por exemplo. Se, por motivos desconhecidos, este processo de reformulação semântica (ou algum processo subjacente de destruição dos enlaces primários) não é equilibrado nesta etapa, verifica-se uma crescente vivência de angústia e malestar, com progressivo sentimento de temor difuso. Tudo parece indicar que este estágio de adoecimento pode se estabilizar, ou avançar, de acordo com certas condições de estruturação, e suportes socioculturais disponíveis, além de características constitucionais individuais. Neste caso, o pior avanço parece ser

18. Ou melhor, com a estrutura do pensamento consciente profundamente comprometido. 
a desorganização do pensamento, gerada pelo estado confusional de quem não consegue se adaptar em um novo mundo, desta vez incompreensível. Neste caso, ou o sujeito se deteriora pela perda da intencionalidade de uma consciência em contínua desorganização secundária, ou parte para um verdadeiro abandono de si mesmo, onde prevalecem, definitivamente, as forças da pulsão de morte.

\section{Referências}

ANDREASEn, N. Linking mind and brain in the study of mental illnesses: a project for a scientific psychopathology. Science, n. 275, p. 1586-92, 1997.

ANGST, J. European long-term follow-up studies of schizophrenia. Schizophrenia Bull., v. 14, n. 4, p. 501-13, 1988.

Bercherie, P. Os fundamentos da clínica. História e estrutura do saber psiquiátrico. Rio de Janeiro: Jorge Zahar, 1989.

Berner, P.; Gabreil, E.; Katschnig, H.; Kieffer, W.; Koehler, K.; Lenz, G.; Nutzinger, D.; Schnada, H.; Simhandl, C. Diagnostic Criteria for Functional Psychosis. Cambridge: World Psychiatry Association, 1992.

Berrios, G. E.; Hauser, R. The early development of Kraepelin's ideas on classification: a conceptual history. Psychological Medicine, n. 18, p. 813-21, 1988.

Berrios, G. E.; Fuentenebro de Diego, F. Delirio. Los paradigmas del debate teórico en las sociedades científicas. Psicopatología, Madrid, v. 18, n. 2, p. 54-8, 1998.

Binswanger, L. Três formas de existência malograda. Rio de Janeiro: Jorge Zahar, 1977.

Bleuler, E. (1911). Demencia Precoz. El grupo de las esquizofrenias. Buenos Aires: Hormé, 1950.

La schizophrénie. Rapport au Congrès des Médecins Aliénistes et Neurologistes. Geneve, Lausanne: Masson, 1926.

Bleuler, M. The long-term course of the schizophrenic psychoses. Psychological Medicine, n. 4, p. 244-54, 1974.

Buchanan, R. W.; Carpenter, W. T. Domains of psychopathology. An approach to the reduction of heterogeneity in schizophrenia. J. Nervous and Mental Disease, v. 182, n. 4, p. 193- 204, 1994.

Ciompi, L. Is there really a schizophrenia? The long-term course of psychotic phenomena. Brit. J. Psychiatry, n. 145, p. 636- 40, 1984.

Ciompi, L.; Dauwalder, H. P.; Maier, C.; Aebi, E.; Trütsch, K.; Kupper, Z.; Rutishauser, C. The pilot project. Soteria Berne. Clinical experiences and results. Brit. J. Psychiatry, 


\begin{tabular}{lrrrrr|l}
$R \quad E$ & $V$ & I & S & T & $A$ \\
LATINOA M ERICANA & \\
DE PSICO PATO LOGIA & \\
F U N D A M E N T A L & \\
ano IX, n. & 4, dez/2006 & \\
\hline
\end{tabular}

n. 161 (suppl. 18), p. 145-53, 1992.

ConRAD, K. La esquizofrenia incipiente. Intento de un análisis de la forma del delirio. Madrid: Editorial Alhambra, 1963.

Delay, J.; Deniker, P. Méthodes chimiothérapiques en psychiatrie. Paris: Masson, 1961.

Devereux, G. Una teoría sociológica de la esquizofrenia. In: Ensayos de etnopsiquiatria general. Barcelona: Barral Editores, 1973.

EAton, W. W. Evidence for universality and uniformity of schizophrenia around the world: assessment and implications. In: Search for the Causes of Schizophrenia. Balance of the Century. Springer: Gattaz and Häfner, 1999. v. IV.

Fish, F. J. The classification of schizophrenia. The views of kleist and his co-workers. J. Ment. Science, v. 432, n. 103, p. 443-63, 1957.

Freud, S. (1900). A interpretação dos sonhos. In: In: Edição Standard Brasileiras das Obras Psicológicas Completas. Rio de Janeiro: Imago, 1976. v. IV e V.

(1911). Notas psicanalíticas sobre um relato autobiográfico de um caso de paranóia (Dementia Paranoides). In: Edição Standard Brasileiras das Obras Psicológicas Completas. Rio de Janeiro: Imago, 1976. v. XII.

(1914). Sobre o narcisismo. In: Edição Standard Brasileiras das Obras Psicológicas Completas. Rio de Janeiro: Imago, 1976. v. XII.

(1915). Inconsciente. In: Edição Standard Brasileiras das Obras Psicológicas Completas. Rio de Janeiro: Imago, 1976. v. XIV.

Goldenstein, N. Sobre o abandono de si mesmo. Um estudo psicopatológico sobre a deterioração esquizofrênica. 2002. Tese (doutorado em Psiquiatria). Instituto de Psiquiatria da UFRJ/IPUB. Mimeo.

HAfNer, H.; Heiden, W. The course of schizophrenia in the light of modern follow-up atudies: the ABC and WHO studies. Eur Arch Neurol Sci, n. 249 (suppl. 4), p. 1426, 1999.

Harding, C. M.; Zubin, J.; Strauss, J. S. Chronicity in schizophrenia: revisited. Brit. J. Psychiatry, n. 161 (suppl. 18), p. 27-37, 1992.

Hauser, D.; Сhomsky, N.; Fitch, W. Science, v. 298, n. 11, p. 1569-1579, 2002.

Hoche, A. (1912). El significado de los complejos sintomáticos en psiquiatría. In: Hoche, Alfred; Kraepelin, Emil; Bumke, Oswald (orgs.). Los síntomas de la locura. Fundación Archivos de Neurobiología. Madrid: Editorial Triacastela, 1999. (Historia y Teoría de la Psiquiatría).

Houaiss, A. Dicionário Houaiss da Língua Portuguesa. Instituto Houaiss da Língua Portuguesa. Rio de Janeiro: Objetiva, 2001. 
HÜBER, G. Avances recientes en la investigación de la esquizofrenia y las perturbaciones relacionadas: aspectos clínicos, psicopatológicos y diagnósticos. Disponível em http:www.alcmeon.com.ar/4/14/a14_01.htm, 1998.

Jablensky, A. The 100-year epidemiology of schizophrenia. In: HäFner, H.; Gattaz, W. F.; JANZARIK, W. (eds.). Search for the Causes of Schizophrenia. Balance of the Century. Springer, 1999. v. IV.

JANZARIK, W. The concept of achizophrenia: history and problems. In: HäFner, H.; Gattaz, W. F.; Janzarik, W. (eds.). Search for the Causes of Schizophrenia. Heidelberg: Springer-Verlag, 1987.

JASPERs, K. (1913). Psicopatologia geral. Rio de Janeiro: Atheneu, 1979.

KLOSTERKÖtTeR, J. The meaning of basic symptoms for the genesis of the schizophrenic nuclear syndrome. Japanese J. Psychiatry. Neurol, v. 46. n. 3, p. 609- 30, 1992.

Koenler, K. G. First rank symptoms of schizophrenia: questions concerning clinical bounderies. Brit. J. Psychiatry, n. 134, p. 236-48, 1979.

Kraepelin, E. Psychiatrie clinique. Paris: Vigot Frères, 1907.

(1920). Las manifestaciones de la locura. In: Hoche, Alfred; Kraepelin, Emil; Bumke, Oswald (orgs.). Los síntomas de la locura. Fundación Archivos de Neurobiología. Madrid: Editorial Triacastela, 1999. (Historia y Teoría de la Psiquiatría). (1932). Memoirs. Germain: Springer-Verlag Berlin, 1987.

LÉvy-Strauss, C. Antropologia estrutural. Rio de Janeiro: Tempo Brasileiro, 1975.

As estruturas elementares do parentesco. Petrópolis: Vozes, 1982.

O pensamento selvagem. Rio de Janeiro: Objetiva, 1986.

Luria, A. R. Pensamento e linguagem. Porto Alegre: Artes Médicas, 1987.

Merleau-Ponty, M. O visível e o invisível. São Paulo: Perspectiva, 2000.

Murphy, J. M. Psychiatric labeling in cross-cultural perspective. Science, n. 191, p. 1019-28, 1976.

Nash, J. F. Jr. Autobiografy. Disponível em http://www.nobel.se/economics/laureates/ 1994/index.html, 1994.

Parry-Jones, W. L. Psychiatry in the people's Republic of China. Brit. J. Psychiatry, n. 148, p. 632- 41, 1986.

Pinker, S. O instinto da linguagem. Rio de Janeiro: Martins Fontes, 2002.

Sartorius, N.; Jablensky, A.; Korten, A.; Ernberg, G.; Anker, M.; Cooper, E.; Day, R. Early manifestation and first-contact incidence of schizophrenia in different cultures. Psychological Medicine, n. 16, p. 909-28, 1986. 
Searle, J. R. A redescoberta da mente. São Paulo: Martins Fontes, 1997.

STERn, D. O mundo interpessoal do bebê. Uma visão a partir da psicanálise e da psicologia do desenvolvimento. Porto Alegre: Artes Médicas, 1992.

Susser, E.; MoJtabai, R. Epidemiology in schizophrenia research: the untapped potential. In: Häfner, H.; Gattaz, W. F.; Janzarik, W. (eds.). Search for the Causes of Schizophrenia. Berlin: Springer-Verlag, 1999.

Wing, J. K. History, classification, and research strategies: discussion. In: HäFNER, H.; GatTAz, W. F.; JanZariK, W. (eds.). Search for the Causes of Schizophrenia. Heidelberg: Springer-Verlag, 1987.

Wing, J. K. e NiXon, J. Discriminating symptoms in schizophrenia. A report from the international pilot study of schizophrenia. Arch. Gen. Psychiatry, n. 32, p. 853- 9, 1975.

World Health Organization (WhO). The International Pilot Study of Schizophrenia. New York: John Wiley \& Sons, 1979.

Zubin, J. Degeneration theory and the stigma of schizophrenia. Biol. Psychiatry, n. 20, p. 1145-8, 1985. 